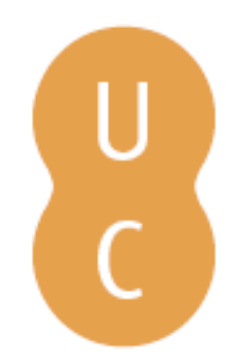

\title{
pommalina
}

\section{Planeamento e gestão urbanística municipal: repercussões no desenvolvimento recente da cidade de Setúbal}

\author{
Autor(es): $\quad$ Silva, Vasco Raminhas da \\ Publicado por: Imprensa da Universidade de Coimbra \\ URL \\ persistente: URI:http://hdl.handle.net/10316.2/30884 \\ DOI: $\quad$ DOI:http://dx.doi.org/10.14195/978-989-26-0244-8_59 \\ Accessed : $\quad$ 26-Apr-2023 09:03:47
}

A navegação consulta e descarregamento dos títulos inseridos nas Bibliotecas Digitais UC Digitalis, UC Pombalina e UC Impactum, pressupõem a aceitação plena e sem reservas dos Termos e Condições de Uso destas Bibliotecas Digitais, disponíveis em https://digitalis.uc.pt/pt-pt/termos.

Conforme exposto nos referidos Termos e Condições de Uso, o descarregamento de títulos de acesso restrito requer uma licença válida de autorização devendo o utilizador aceder ao(s) documento(s) a partir de um endereço de IP da instituição detentora da supramencionada licença.

Ao utilizador é apenas permitido o descarregamento para uso pessoal, pelo que o emprego do(s) título(s) descarregado(s) para outro fim, designadamente comercial, carece de autorização do respetivo autor ou editor da obra.

Na medida em que todas as obras da UC Digitalis se encontram protegidas pelo Código do Direito de Autor e Direitos Conexos e demais legislação aplicável, toda a cópia, parcial ou total, deste documento, nos casos em que é legalmente admitida, deverá conter ou fazer-se acompanhar por este aviso.

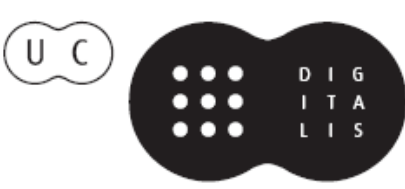




\section{TRUNFOS DE UMA}

\section{EOGRAFIA ACIVA}

\section{DESENVOLVIMENTO LOCAL,}

AMBIENTE,

ORDENAMENTO

E TECNOLOGIA

Norberto Santos

Lúcio Cunha

COORDENAÇÃO 
Vasco Raminhas da Silva

Câmara Municipal de Setúbal

\section{PLANEAMENTO E GESTÃO URBANÍSTICA MUNICIPAL - REPERCUSSÓES NO DESENVOLVIMENTO RECENTE DA CIDADE DE SETÚBAL}

\section{Os Ciclos de Desenvolvimento ECONÓMico e o Processo de URBAnizaÇÃo}

O desenvolvimento urbano de Setúbal nas últimas décadas fez-se em função dos ciclos económicos que marcaram a vida da cidade (Figura 1). Períodos de maior crescimento demográfico associados a processos de industrialização, alternaram com períodos de decréscimo e estabilização populacional, em resultado de conjunturas económicas menos favoráveis. O porto, elemento marcante na estrutura urbana da cidade, esteve associado a esses ciclos de desenvolvimento, desde o apogeu da indústria conserveira em finais do século XIX e início do século XX até ao desenvolvimento da indústria automóvel na região nos anos mais recentes.

O modelo de cidade compacta que caracterizou Setúbal até meados dos anos 50 sofre profundas transformaçóes nas décadas seguintes. O Plano Geral de Urbanizaçáo da Cidade de Setúbal (concluído em 1944), num contexto de estagnação económica associado ao encerramento de várias fábricas conserveiras, estabelece uma estratégia de crescimento urbano orientada para Norte, ancorada na abertura de uma nova via urbana (actual Avenida Dr. António Rodrigues Manito) e em intervençóes públicas, de iniciativa municipal e estatal, nomeadamente a construção de equipamentos sociais e bairros de habitação económica em localizaçóes periféricas ao centro da cidade. Inicia-se aqui o processo de expansão da cidade para Norte.

A partir dos anos 60, com os grandes investimentos em novas unidades industriais a Nascente e a criação de milhares de postos de trabalho no concelho de Setúbal, desponta o interesse dos promotores imobiliários, vislumbrando novas oportunidades de negócio. Assiste-se às transferências de propriedade de extensas áreas rurais junto à cidade, ao licenciamento de vários loteamentos privados nesses terrenos (possibilitados a partir de 1965) e, em grande parte dos casos, ao abandono da actividade agrícola. A renda fundiária dispara a partir daí. No entanto, a expansão urbana de Setúbal neste período pode dividir-se em duas fases: a primeira, ao longo da década de 60, corresponde ao crescimento lento da cidade, sendo o processo de urbanizaçáo ainda em pequena escala e liderado por actores locais; a segunda, com início na década de 70, corresponde ao crescimento "explosivo", coincidindo com o comprometimento efectivo do capital financeiro no negócio imobiliário.

Assistiu-se assim a uma progressiva dispersão e descontinuidade dos tecidos urbanos e ao aumento dos espaços vazios e expectantes no interior do perímetro da cidade, situação que se 
repete na década de 90 e primeiros anos da década seguinte. Essas áreas expectantes mantiveram-se durante vários anos, revelando a ausência de uma estratégia de programação do solo urbano por parte da Administração, assente em critérios de racionalidade económica e ambiental.

Figura 1 - Ciclos de desenvolvimento da cidade de Setúbal

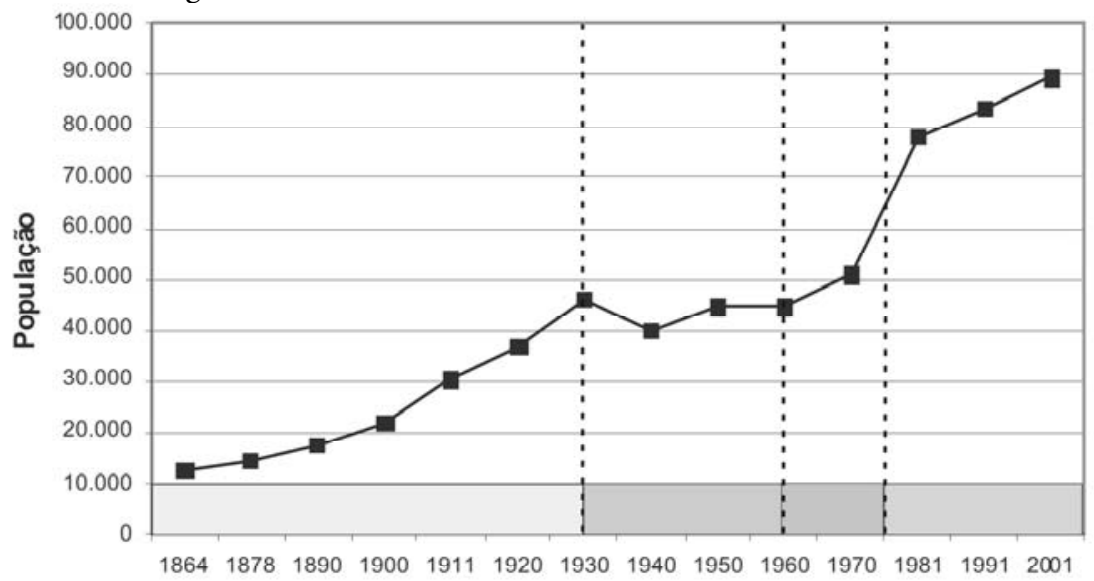

Anos

Crescimento económico e demográfico: ciclo conserveiro

Cidade compacta: desenvolvimento urbano ao longo do rio

Estagnaçào económica e demográfica

Investimento em Obras Públicas: Início do crescimento da Cidade para Norte

Crescimento económico e demográfico:

forte industrialização e urbanização da cidade

Colapso do modelo de industrialização dos anos 70

Tercearizaçào da Cidade e expansão urbana

Fonte: Elaboração própria. INE, Recenseamentos Gerais da População.

Só na década de 80 as áreas intersticiais expectantes sofreram uma redução, indiciando que o processo de urbanização terá sido em parte orientado para a colmatação desses espaços em detrimento da abertura de novas frentes de urbanização. A crise económica instalada parece ter contribuído para travar o ímpeto de expansão urbana para as periferias. No que respeita à área ocupada por grandes equipamentos colectivos e áreas verdes urbanas, verifica-se o aumento da sua representatividade na cidade desde a década de 80 , facto que se pode justificar por uma maior preocupação na prática urbanística no que respeita à programação deste tipo de espaços, assim como uma regulamentação mais exigente neste domínio. Até então a representatividade destas áreas no perímetro da cidade diminui nas décadas de 60 e 70, evidenciando o desequilíbrio entre a significativa expansão urbana que se dá neste período e o necessário investimento em novos equipamentos de apoio à populaçáo e em áreas verdes de recreio e lazer.

O elevado crescimento da construçáo de alojamentos de iniciativa privada nos últimos anos resultou da conjugaçáo de vários factores, nomeadamente da maior facilidade no acesso ao crédito bancário para aquisição de habitação própria e da incipiente regulação do mercado de solos por parte do Município. No entanto, não obstante o crescimento da 
oferta de habitação de iniciativa privada, pública e cooperativa, persiste a dificuldade de acesso a habitação condigna pelos grupos sociais menos solventes.

A expansão urbana de Setúbal neste período é assim dominada pela urbanização de áreas destinadas predominantemente a edifícios residenciais plurifamiliares. As áreas de edifícios residenciais unifamiliares apresentam uma evolução crescente nas últimas décadas, embora tenha sido a partir da década de 90 que o crescimento da cidade passa a ser regido pela construção de vastas áreas de edifícios habitacionais unifamiliares na periferia a Nascente, suplantando em superfície ocupada as áreas residenciais de edifícios plurifamiliares construídas a partir dessa data. A melhoria das condiçôes económicas da população a partir da segunda metade da década de 90, associada a um aumento da taxa de motorização, poderá estar na base da expansão das áreas residenciais unifamiliares. Porém, actualmente subsistem na periferia da cidade (a Norte e a Nascente) vastas áreas loteadas e infra-estruturadas, destinadas na sua maioria a habitação unifamiliar, e com uma baixa percentagem de ocupação.

Com a terciarização da cidade, iniciada na segunda metade da década de 80 e que se prolonga até à actualidade, a população cresce, embora a ritmos mais modestos que anteriormente. A dinâmica na construção de alojamentos acompanha essa tendência de evolução positiva embora com ritmos de crescimento superiores, suportados por um processo de urbanização que continua a privilegiar uma lógica expansiva. A terciarização da base económica da cidade é evidenciada pelo aumento significativo da área afecta aos usos terciários na década de 90 e primeiros anos da década seguinte, fundamentalmente associado à implantação de grandes superfícies comerciais retalhistas, concentradas em localizações periféricas de elevada acessibilidade.

\section{As ORIENTAÇÓES DE PlaneAmento}

A prática urbanística na cidade de Setúbal nos últimos 60 anos ficou marcada por diversos instrumentos de planeamento, uns da iniciativa municipal, outros de iniciativa da Administração Central (Figura 2). Ao longo deste período temporal sucederam-se diferentes abordagens conceptuais e legais quanto à intervençáo da Administraçáo no domínio do planeamento e da gestáo urbanística, com repercussóes directas no território e na resolução dos problemas das populaçóes. Nas orientaçôes de planeamento da Administração Central destacam-se o Plano Director da Região de Lisboa (PDRL), o Plano Regional de Ordenamento do Território da Área Metropolitana de Lisboa (PROT-AML) e o Plano Integrado de Setúbal (PIS). Relativamente às orientaçóes de planeamento decorrentes da Administração Local destacam-se o Plano Geral de Urbanização (PGU) da Cidade de Setúbal, o Plano Concelhio de Setúbal (PCS) e o Plano Director Municipal (PDM).

O PDRL e o PROT-AML destacam o papel de Setúbal, em conjunto com Palmela e, mais recentemente, com o Pinhal Novo, como um importante eixo urbano no desenvolvimento da Área Metropolitana de Lisboa. Apesar do PROT-AML classificar Setúbal como pólo sub-regional vocacionado para equipamentos e serviços, os dois instrumentos consignam o desenvolvimento industrial da Península da Mitrena. A classificação da cidade de Setúbal no PROT-AML como "área urbana a articular/ /requalificar", nomeadamente a nível das acessibilidades locais e metropolitanas, na qualificação dos núcleos degradados, na criação e valorização do espaço público associado à implementação da rede ecológica metropoli- 
tana, na protecção das áreas ribeirinhas e na sua afectação a funções de recreio e lazer e na reconversão de áreas industriais obsoletas e abandonadas para actividades económicas e de usufruto público não teve consequências relevantes a nível territorial.

O PIS, embora sendo um plano da Administração Central, teve uma incidência local, propondo para a zona Nascente da cidade de Setúbal 22 mil fogos destinados a resolver as carências habitacionais sentidas em meados dos anos 70. Porém, a crise energética e o desmoronamento do modelo de desenvolvimento industrial até aí vigente, alteraram de forma substancial os propósitos iniciais do Plano. A revisão do PIS em 1995, segundo o formato de plano de urbanizaçáo, não chegou a ser aprovada superiormente, não ganhando o carácter vinculativo pretendido para a gestão urbanística desta parcela do território.

O PGU, aprovado em 1944, e formatado segundo a figura de Anteplano nas revisóes subsequentes (1955, 1962 e 1972), vigorou formalmente até à entrada em vigor do PDM em 1994. O modelo urbano aponta o sentido de crescimento da cidade para Norte e aposta, nas versóes mais recentes, no desenvolvimento da indústria. As revisóes efectuadas serviram para legitimar as diversas operaçóes urbanísticas que foram sendo concretizadas ao arrepio do plano, embora houvesse algum controle a nível do desenho urbano (traçado dos arruamentos e delimitação dos polígonos dos lotes) por parte do urbanista responsável pelo Plano. De referir que muitos dos equipamentos construídos na década de 50, e enquadrados por este instrumento, são ainda hoje elementos notáveis da estrutura urbana da cidade consolidada.

O PCS inflecte para Nascente o sentido da orientação de expansão da cidade consignada no PGU e aposta na indústria e no porto como principais sustentáculos da base económica concelhia. Apesar de nunca aprovado superiormente, o plano serviu de referencial à gestão urbanística da cidade, embora, por vezes, o estatuto legal náo vinculativo abrisse as portas a que a Administração actuasse de forma casuística na apreciação dos processos urbanísticos, favorecendo assim a especulação imobiliária. A estratégia urbanística centra-se na densificação da ocupação urbana, suportada pelo aumento das áreas de equipamento, e procura contrariar a estrutura concêntrica dada pelos planos anteriores.

Decorridos 50 anos sobre o PGU, Setúbal, com a publicação do PDM em 1994, volta a ter um instrumento de planeamento vinculativo. Este plano aposta na terciarização da base económica municipal, embora preconize a consolidaçáo do sector secundário a Nascente. É também nesse sentido que orienta o crescimento da cidade, com um cunho expansionista (assente em áreas habitacionais de baixa densidade e áreas de terciário), apesar da reabilitaçáo urbana do Centro Histórico e da frente ribeirinha constarem igualmente das medidas programáticas, embora nunca executadas. Retoma propostas de planos anteriores, nomeadamente a correcção da estrutura concêntrica da cidade através da execução de vias circulares. Algumas medidas de gestão urbanística e fundiária, consignadas no PDM, revelaram não ter aplicabilidade ou foram ignoradas pela Autarquia.

O desenvolvimento da cidade de Setúbal nas últimas décadas tomou o rumo da expansão e da dispersão de uma forma pouco racional e programada. Muitos dos planos elaborados para Setúbal, sobretudo os de incidência local, não foram aprovados superiormente. Estes instrumentos, sem carácter vinculativo, foram utilizados como referencial na gestáo urbanística, embora dando abertura a actuaçóes casuísticas por parte da Administração. $\mathrm{O}$ planeamento teve um papel incipiente na construção da cidade de Setúbal e na gestão do respectivo processo de urbanização, revelando problemas ligados à execuçáo dos planos. Os poucos mecanismos que permitiriam à Administração assumir um papel mais activo na conduçáo do processo de urbanização e na consolidação de uma política de solos municipal 
foram sendo sistematicamente postos de lado, através da não aprovação dos planos ou justificando a ausência de suporte legal para os colocar em prática.

Nos anos mais recentes, o PDM constituiu o único referencial de planeamento vinculativo. O patamar intermédio da escala de planeamento urbano, suportado pelos planos de urbanizaçáo e planos de pormenor, onde é definida com maior rigor a programaçáo urbana, o desenho das malhas, a localização dos equipamentos e dos espaços de utilização colectiva, foi basicamente suprimido. Poucos foram os planos de pormenor elaborados e aprovados, tendo na sua maioria correspondido a alteraçóes de usos definidos no PDM e à viabilização de novas áreas de expansão urbana em áreas periféricas à cidade de Setúbal e sem preocupaçóes efectivas de estruturação e qualificação urbana, como é exemplo o Plano de Pormenor de Vale de Mulatas e o Plano de Pormenor da Quinta do Vale da Rosa e Zona Oriental de Setúbal I.

Passou-se directamente do zonamento e dos parâmetros urbanísticos genéricos apontados no PDM para o projecto de loteamento urbano, circunscrito à divisão cadastral e, na maior parte das vezes, ausente de qualquer lógica de articulaçáo com os tecidos envolventes.

Figura 2 - Principais orientaçóes de planeamento para a cidade de Setúbal

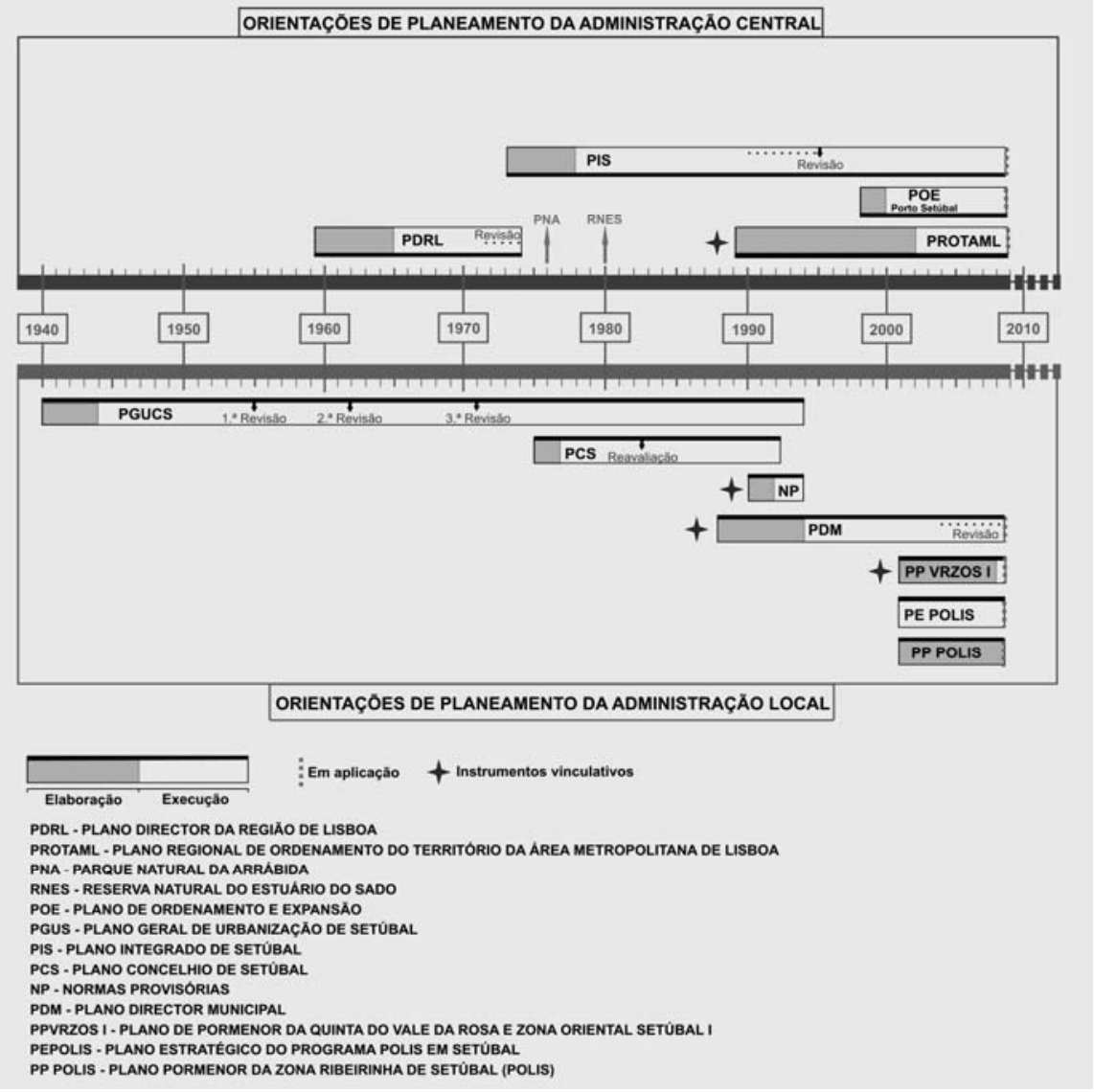

Fonte: Elaboraçáo própria. 


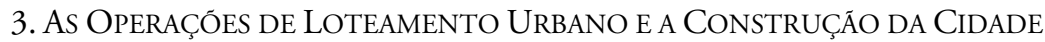

Para a avaliação da importância das operaçôes de loteamento urbano no crescimento da cidade de Setúbal nas últimas décadas foi definida uma amostra constituída por 20 alvarás de licença de loteamento urbano, com uma representatividade de cerca de $44 \%$ relativamente ao número total de fogos previstos no universo de análise (145 alvarás de licença de loteamento urbano). A análise centrou-se em 6 grandes domínios: processo de tramitação / dinâmica; tipo de promotor e objectivos da promoção; características dos modelos urbanos propostos; enquadramento face aos planos municipais; contributo para a estruturaçáo da cidade; e grau de execução.

$\mathrm{O}$ recurso a este instrumento assume uma maior importância no final da década de 60/início da década de 70 e no período posterior a 1990, associado a conjunturas económicas favoráveis e a uma elevada dinâmica urbanística. O processo de tramitação revelou-se, em geral, lento, como resultado da conjugação da má instrução dos processos por parte dos promotores e da incapacidade dos serviços técnicos municipais responderem em tempo útil às solicitaçóes. A produção legislativa após o 25 de Abril de 1974, associada a preocupaçóes efectivas na regulação do processo de urbanização e na salvaguarda dos recursos naturais, e o não cumprimento por parte dos promotores das obrigaçôes relativas às obras de urbanização, contribuíram para que alguns processos de loteamento se arrastassem no tempo.

O processo de urbanização tem sido liderado pela iniciativa privada, em especial por empresas ligadas ao sector imobiliário e à construção civil. Outros agentes locais, associados a domínios de actividade distintos, nomeadamente empresas, instituiçóes particulares de solidariedade social e clubes desportivos, tiveram importância na promoção de novas áreas urbanas, ainda que a sua intervenção se tenha pautado, regra geral, por objectivos meramente especulativos e ausente de mais valias para a estruturação e qualificação da cidade. A promoção imobiliária orientou-se maioritariamente para o mercado livre. A produçáo de fogos a custos controlados representou menos de $1 / 5$ do total de fogos licenciados e estáo associados a loteamentos urbanos antigos, o que atesta a atitude passiva do Município no mercado da habitação nos últimos anos.

O enquadramento dos loteamentos urbanos relativamente aos planos locais revela uma diversidade de situaçóes. Assim, os loteamentos urbanos contemporâneos do PGU (a maioria em termos de representatividade da amostra quanto ao número de fogos) não foram influenciados pelo plano, mas sim sujeitos a aprovação pelo urbanista autor do plano. O PCS, não sendo um instrumento vinculativo, serviu muitas vezes de referencial aos projectos de loteamento urbano, embora em diversas situaçóes essa condição permitiu à Administração adoptar uma atitude casuística, ultrapassando as orientaçóes do plano, com motivaçóes manifestamente especulativas. O PDM, enquanto instrumento de planeamento vinculativo, determinou a formataçáo dos loteamentos aprovados durante o seu período de vigência, embora em muitos casos a aplicaçáo das regras para a cedência de terrenos para o domínio municipal foram muitas vezes deturpadas, com um evidente prejuízo para o Município.

Os modelos urbanos preconizados nos loteamentos licenciados assentam maioritariamente no domínio dos usos habitacionais, tipologias de malhas urbanas que garantem uma maior densificação das áreas loteadas, altas densidades habitacionais e ausência de logradouro no interior dos lotes. Apesar da importância relativa dos terrenos objecto de loteamento afectos a espaço público, tal situação é muito influenciada pelas áreas ocupadas pelas vias de circulação, estacionamento e em alguns casos pela dimensão significativa de áreas cedidas para 
espaços verdes que coincidem com áreas sujeitas a várias restrições de utilidade pública que impedem a sua urbanização. Nos anos mais recentes tem-se assistido a novas áreas de expansão urbana nas franjas periféricas da cidade, assentes em modelos de ocupação de habitação unifamiliar e de baixa densidade. Só uma pequena parte dos loteamentos urbanos, principalmente os mais antigos, deram algum contributo para a estruturação da cidade, mediante a cedência de terrenos para equipamentos, parques verdes e alguns arruamentos de maior importância. Todavia, a situação mais comum é a de défice nas áreas cedidas para equipamentos e espaços verdes e, muitas vezes, não há registo de compensaçóes para o Município. A avaliação dos níveis de execução dos loteamentos urbanos da amostra revela que cerca de $28,5 \%$ da área bruta de construção prevista está ainda por concretizar.

\section{CONCLUSÓES}

A actuação da Câmara Municipal na gestão do processo de urbanização da cidade de Setúbal pautou-se pelo reduzido investimento no planeamento urbanístico, designadamente na elaboração e aprovaçáo de planos de urbanizaçáo e planos de pormenor, centrando no loteamento urbano a função principal de formatação dos novos espaços de cidade, delegando nas iniciativas dos particulares a responsabilidade de desenhar a cidade. A utilizaçáo deste instrumento, sem a definição prévia de uma estrutura urbana e numa lógica de evidente especulação imobiliária, tem servido para viabilizar novas frentes de urbanização, caracterizadas pela rentabilização máxima da capacidade edificável da parcela, pela configuração de malhas urbanas subjugadas à delimitação cadastral, pela ausência de articulação com os tecidos envolventes e pelo défice de cedências para equipamentos, espaços verdes e espaços de utilização colectiva. Os resultados observáveis revelam um processo de urbanização extensivo e fragmentado, ausente de qualquer estratégia de programação e estruturação urbana, traduzindo-se em espaços de cidade desqualificados.

\section{REFERÊNCIAS BIBLIOGRÁFICAS}

Faria, Carlos Vieira (1980), Novo Fenómeno Urbano da Aglomeração de Setúbal; ensaio de sociologia urbana; Assírio e Alvim, textos de ciências sociais / 18; Lisboa.

Pereira, Margarida (Direcção e Coordenação) (2007), Setúbal, a cidade e o Rio - Revalorizar a frente ribeirinha; SetúbalPolis.

Silva, Vasco Raminhas (2009), Planeamento e Gestão Urbanistica na Cidade de Setúbal no Período 1944 - 2004,

Dissertação de Mestrado apresentada ao IST/UTL, Lisboa. 